\title{
A rare cause of abdominal pain and bowel obstruction
}

\author{
Abdelfatah MM* and Hurley J \\ Division of Gastroenterology, Hepatology and Nutrition, East Carolina University, Greenville, North Carolina, USA
}

A 57 y/o Caucasian Female presents to the outside hospital with diffuse abdominal pain, nausea, vomiting. She was unable to tolerate her diet for two days while complaining of new onset constipation and abdominal distention. The patient describes this pain as diffuse, worsening with movement. Serum studies consisting of a complete blood count and complete metabolic panel were within normal limits. CT scan from was consistent with large bowel obstruction. Several days later, he patient was admitted to our hospital and repeat CT scan was demonstrated colitis in the distal left colon and URQ. The CT scan was also significant for a new onset pneumobilia and a two $\mathrm{cm}$ round structure blocking the junction between the descending and sigmoid colon (Figures 1 and 2).

This is a case of spontaneous cholecystocolonic fistulae with impacted gallstone causing a large bowel obstruction.

Spontaneous cholecystocolonic fistulae is a rare complication of gall bladder disease, comprise only $0.06 \%-0.14 \%$ of patients with biliary disease [1].

The majority of cholecystocolonic fistulae is an incidental finding during cholecystectomy [2]. Symptomatic fistulae can present with abdominal pain, weight loss, and diarrhea. Chronic diarrhea, leading to malabsorption and steatorrhea, had been reported in spontaneous

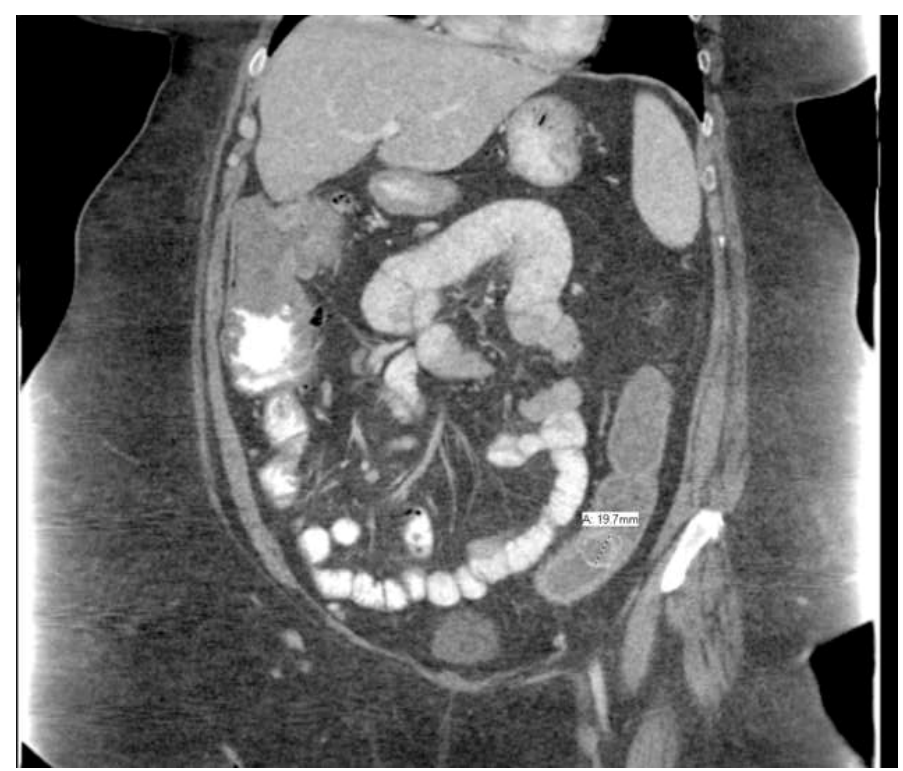

Figure 1. CT scan image demonstrate a round structure at the descending colon

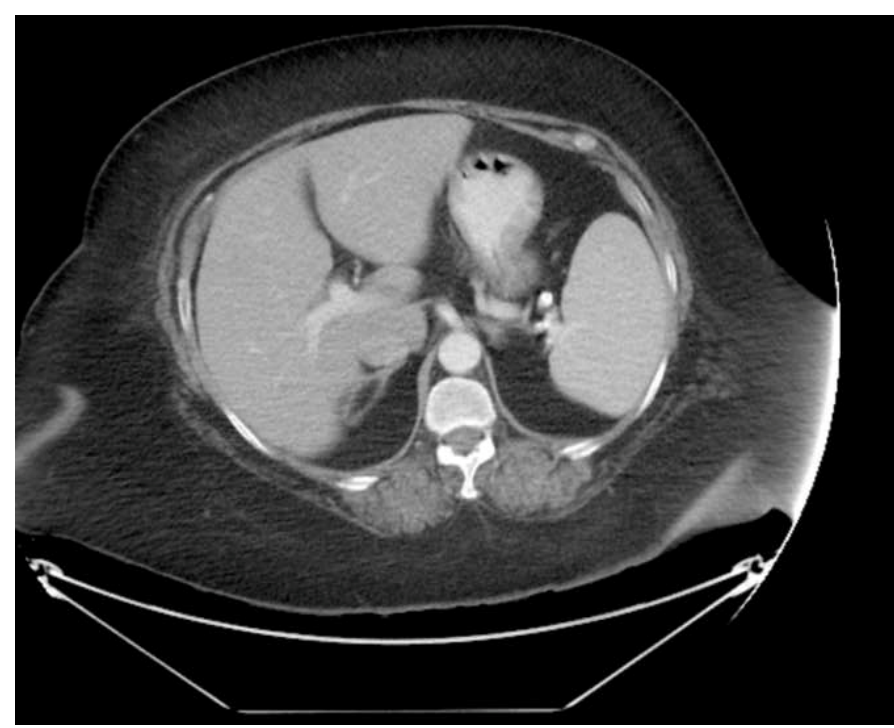

Figure 2. CT scan image demonstrate pneumobilia

cholecystocolonic fistulae due to loss of bile acids through the fistula to the colon.

Our patient presented with abdominal pain and partial bowel obstruction from the gall stone. Large bowel obstruction was reported secondary to impaction of a large gallstone in the colon. [3]

Conservative management and spontaneous passage of the stone was observed in our patient. Providers should maintain a high index of suspicion of a cholecystocolonic fistula in elderly patients presenting with pneumobilia or persistent diarrhea of unknown etiology.

\section{Acknowledgment}

The author of the manuscript has no financial, professional, or personal conflict of interest to declare. Mohamed Abdelfatah and John Hurley drafted the manuscript and approved the final version.

Correspondence to: Mohamed Abdelfatah, Department of Internal Medicine, Division of Gastroenterology, Hepatology, and Nutrition, East Carolina University, USA, E-mail: dr.mohamed.magdy@hotmail.com

Received: February 20, 2018; Accepted: March 06, 2018; Published: March 09, 2018 


\section{References}

1. Glenn F, Reed C, Grafe WR (1981) Biliary enteric fistula. Surg Gynecol Obstet 153: 527-532.

2. Chowbey PK, Bandyopadhyay SK, Sharma A, Khullar R, Soni V, at al (2006) Laparoscopic management of cholecystoenteric fistulas. J Laparoendosc Adv Surg Tech A 16: 467-472. [Crossref]
3. Correia MFS, Amonkar DP, Nayak SV, Menezes J-LAS (2009) Cholecystocolic Fistula: A Diagnostic Enigma. Saudi Journal of Gastroenterology: Official Journal of the Saudi Gastroenterology Association. 15:42-44. [Crossref]

Copyright: (C2018 Abdelfatah MM. This is an open-access article distributed under the terms of the Creative Commons Attribution License, which permits unrestricted use, distribution, and reproduction in any medium, provided the original author and source are credited. 